\title{
Immunohistochemical staining of tumor necrosis factor- $\alpha$ and interleukin-10 in benign and malignant ovarian neoplasms
}

\author{
MILLENA PRATA JAMMAL ${ }^{1}$, ALLISON ARAÚJO DA SILVA ${ }^{1}$, AGRIMALDO MARTINS FILHO ${ }^{1}$, \\ ELIÂNGELA DE CASTRO CÔBO ${ }^{2}$, SHEILA JORGE ADAD ${ }^{2}$, \\ EDDIE FERNANDO CANDIDO MURTA ${ }^{1}$ and ROSEKEILA SIMÕES NOMELINI ${ }^{1}$ \\ ${ }^{1}$ Research Institute of Oncology (IPON)/Discipline of Gynecology and Obstetrics, and \\ ${ }^{2}$ Department of Special Pathology, Federal University of Triângulo Mineiro (UFTM), 38025-440 Uberaba, MG, Brazil
}

Received May 11,2014; Accepted November 21, 2014

DOI: $10.3892 / 01.2014 .2781$

\begin{abstract}
Ovarian cancer is the ninth most common malignancy and the fifth leading cause of cancer death in women in the USA. The majority of malignant tumors of the ovary are diagnosed at an advanced stage, making it the most fatal gynecological cancer. The aim of the current study was to determine whether there are differences in immunohistochemical tissue staining of cytokine tumor necrosis factor- $\alpha(\mathrm{TNF}-\alpha)$ and interleukin-10 (IL-10) between benign tumors and malignant primary ovarian cancer. In total, 28 patients undergoing surgery for ovarian cysts were evaluated, and a diagnosis of benign neoplasm $(n=14)$ or malignant neoplasm $(n=14)$ was determined. An immunohistochemical study of histological sections of ovarian tumors was conducted. The results were analyzed using Fisher's exact test, with $\mathrm{P}<0.05$ indicating a statistically significant difference. Immunohistochemical staining of IL-10 was increased in malignant tumors compared with benign tumors $(\mathrm{P}=0.0128)$. For TNF- $\alpha$, the immunohistochemical staining was more intense in malignant neoplasms, however, a statistically significant difference was not observed. These results indicate that the analysis of cytokines may be useful as a potential tissue marker of ovarian malignancy.
\end{abstract}

\section{Introduction}

Ovarian cancer is one of the most fatal malignant gynecological neoplasms (1), with the majority of tumors having reached an advanced stage prior to diagnosis. The predominant therapeutic strategy is debulking surgery followed by

Correspondence to: Professor Rosekeila Simões Nomelini, Research Institute of Oncology (IPON)/Discipline of Gynecology and Obstetrics, Federal University of Triângulo Mineiro (UFTM), Avenue Getúlio Guaritá, 214 Bairro Abadia, 38025-440 Uberaba, MG, Brazil

E-mail: rosekeila@terra.com.br

Key words: ovarian cancer, ovarian neoplasms, interleukin-10, tumor necrosis factor- $\alpha$, immunohistochemical staining chemotherapy. Despite chemotherapeutic treatment with platinum and taxane derivatives, the five-year survival rate for stages III and IV is only $5-15 \%$, while for stages I and II, it is $80-95 \%(2,3)$.

The sensitivity and specificity of gynecological screening for ovarian neoplasms are limited (4). Ultrasound may aid in the diagnosis of ovarian tumors and differentiation between neoplastic and non-neoplastic tumors $(5,6)$; additionally, color Doppler can increase the specificity of transvaginal ultrasound $(7,8)$. However, the early diagnosis of ovarian cancer by ultrasound may be challenging due to its low prevalence in the general population decreases the positive predictive value of the screening test $(9,10)$.

Large numbers of leukocytes, particularly mononuclear cells such as lymphocytes and tumor-associated macrophages (TAMs), may be identified in the tumor stroma (11) and malignant effusions (12), and are able to produce Th1 and Th2 type cytokines. A progressive shift in the production of cytokines by TAMs (from Th1 to Th2 type) may occur during tumor progression, reducing the immune response to the tumor (12).

Recent studies have demonstrated the importance of tumor necrosis factor- $\alpha$ (TNF- $\alpha$ ) in promoting tumor growth and in the progression of ovarian malignancies $(13,14)$. Additionally, Zhou et al assessed the expression of IL-10 in primary ovarian carcinoma, and observed that the tissue level of this cytokine was significantly higher in ovarian cancer compared with benign and normal controls (15). Furthermore, the malignant cases also showed significantly high IL-10 levels in the serum and ascitic fluid, suggesting that malignant cells can synthesize interleukin, which likely assists in the promotion and development of ovarian carcinoma. The tumor microenvironment differs between benign, malignant and non-neoplastic tumors, indicating a role of cytokines in tumor progression (16). A progressive shift in the production of cytokines may occur during tumor progression. Cytokines can stimulate cell growth and contribute to metastasis. Thus, cytokines may be useful tissue markers in determining ovarian malignancy.

The aim of the present study was to determine whether differences exist in immunohistochemical staining of cytokines, TNF- $\alpha$ and interleukin-10 (IL-10) between benign tumors and malignant primary ovarian tumors. 
Table I. Qualitative variables of patients and tumor staging.

\begin{tabular}{|c|c|c|c|c|}
\hline \multirow[b]{2}{*}{ Variable } & \multicolumn{2}{|c|}{ Malignant neoplasms $(n=14)$} & \multicolumn{2}{|c|}{ Benign neoplasms $(n=14)$} \\
\hline & $\mathrm{n}$ & $\%$ & $\mathrm{n}$ & $\%$ \\
\hline \multicolumn{5}{|c|}{ Hormonal status } \\
\hline Menacme & 6 & 42.86 & 10 & 71.43 \\
\hline Menopause & 8 & 57.14 & 4 & 28.57 \\
\hline \multicolumn{5}{|c|}{ Smoking status } \\
\hline Yes & 9 & 64.28 & 5 & 35.71 \\
\hline No & 5 & 35.72 & 9 & 64.29 \\
\hline \multicolumn{5}{|c|}{ Family history of cancer } \\
\hline Yes & 2 & 14.28 & 3 & 21.43 \\
\hline No & 12 & 85.72 & 11 & 78.57 \\
\hline \multicolumn{5}{|c|}{ Previous history of cancer } \\
\hline Yes & 0 & 0.00 & 0 & 0.00 \\
\hline No & 14 & 100.00 & 14 & 100.00 \\
\hline \multicolumn{5}{|l|}{ Stage } \\
\hline IA & 5 & 42.86 & & \\
\hline $\mathrm{IC}$ & 2 & 14.28 & & \\
\hline IIIB & 1 & 7.14 & & \\
\hline IIIC & 5 & 42.86 & & \\
\hline IV & 1 & 7.14 & & \\
\hline
\end{tabular}

\section{Materials and methods}

Patients. In total, 28 patients were evaluated in the Pelvic Mass Clinic, Oncological Research Institute/Discipline of Gynecology and Obstetrics, Federal University of Triângulo Mineiro (Uberaba, Brazil), and subsequently underwent surgical treatment in accordance with pre-established criteria, following which a diagnosis of benign neoplasm $(n=14)$ or malignant neoplasm $(n=14)$ of the ovary was confirmed. The indication criteria for laparotomy were as follows: Anechoic cysts with a maximum diameter $<7.0 \mathrm{~cm}$, persistence of change for more than six months and normal tumor markers; tumor markers changed; anechoic cysts with a maximum diameter $\geq 7.0 \mathrm{~cm}$; solid ovarian tumor, presence of intracystic vegetation, thick septa, two or more thin septa; and a color Doppler resistance index $\leq 0.4(17,18)$.

Inclusion criteria were the postoperative diagnosis of primary ovarian malignancy or benign neoplasm by pathological analysis of paraffin-embedded tissue sections. Exclusion criteria were the presence of adnexal torsion of the pedicle, rupturing of the cyst during surgery, secondary ovarian malignancy (metastasis), chemotherapy treatment prior to surgery and recurrence.

The study was reviewed and approved by the ethics committee of the Federal University of Triângulo Mineiro. Written informed consent was obtained from each patient or a family member.

Pathological analysis. Pathological analysis was conducted by the Federal University of Triângulo Mineiro Surgical Pathology Service. Tissue samples were embedded in paraffin and analyzed by an experienced pathologist. The pathological evaluation and staging of the cases were performed according
Table II. Types of tumors determined by histopathological analysis.

\begin{tabular}{llr}
\hline Tumor type & $\mathrm{n}$ & $\%$ \\
\hline Benign neoplasms (n=14) & & \\
Mucinous cystadenoma & 7 & 50.00 \\
Serous cystadenoma & 3 & 21.43 \\
Benign cystic teratoma & 3 & 21.43 \\
Serous cistoadenofibroma & 1 & 7.14 \\
Malignant neoplasms (n=14) & & \\
Borderline mucinous cystadenoma & 1 & 7.14 \\
Mucinous cistoadenocarcinoma & 1 & 7.14 \\
Papillary serous adenocarcinoma & 1 & 7.14 \\
Endometrioid adenocarcinoma & 1 & 7.14 \\
Anaplastic papillary adenocarcinoma & 1 & 7.14 \\
Ovarian carcinoid & 1 & 7.14 \\
Granulosa cell tumor associated & 1 & 7.14 \\
$\quad$ with Brenner tumor & & \\
Squamous cell carcinoma teratoma & 1 & 7.14 \\
Granulosa cell tumor & 2 & 14.28 \\
Dysgerminoma & 2 & 14.28 \\
Serous cistoadenocarcinoma & 2 & 14.28 \\
\hline
\end{tabular}

to the criteria of the International Federation of Gynecology and Obstetrics (19).

Immunohistochemistry. Paraffin blocks containing representative samples of tumors were selected from a review of 
Table III. Immunohistochemical staining of TNF- $\alpha$ and IL-10 in benign and malignant ovarian neoplasms.

\begin{tabular}{|c|c|c|c|c|c|c|c|c|}
\hline & \multicolumn{4}{|c|}{ TNF- $\alpha$ staining } & \multicolumn{4}{|c|}{ IL-10 staining } \\
\hline & \multicolumn{2}{|c|}{ Score $2-3$} & \multicolumn{2}{|c|}{ Score $0-1$} & \multicolumn{2}{|c|}{ Score $2-3$} & \multicolumn{2}{|c|}{ Score $0-1$} \\
\hline & $\mathrm{n}$ & $\%$ & $\mathrm{n}$ & $\%$ & $\mathrm{n}$ & $\%$ & $\mathrm{n}$ & $\%$ \\
\hline Benign neoplasms $(n=14)$ & 5 & 35.7 & 9 & 64.3 & 6 & 42.9 & 8 & 57.1 \\
\hline Malignant neoplasms $(n=14)$ & 8 & 57.1 & 6 & 42.9 & 13 & 92.9 & 1 & 7.1 \\
\hline
\end{tabular}

$\mathrm{P}=0.4495$ (TNF- $\alpha$ ) and $\mathrm{P}=0.0128$ (IL-10). TNF- $\alpha$, tumor necrosis factor- $\alpha$; IL-10, interleukin-10.

the original slides. Specimens obtained from surgical resection were fixed in $10 \%$ formalin prior to being processed in paraffin. Hematoxylin-eosin-stained sections were reviewed by a pathologist and a representative section for each case was selected for immunohistochemical analysis.

Selected sections were deparaffinized, rehydrated, and heated in a microwave oven in $0.01 \mathrm{M}$ citrate buffer (pH 6.0; Química Contemporânea, Diadema, Brazil) for $30 \mathrm{~min}$. Endogenous peroxidase activity was blocked by $3 \%$ hydrogen peroxide for $10 \mathrm{~min}$, followed by a wash with phosphate buffered saline. The sections were incubated overnight at $4^{\circ} \mathrm{C}$ with the following primary antibodies: Anti-TNF (rabbit polyclonal IgG, $100 \mu \mathrm{g} / \mathrm{ml}, 1: 50$ dilution, cat. no. sc-130220; Santa Cruz Biotechnology, Inc., Dallas, TX, USA) and anti-IL-10 (rabbit polyclonal $\mathrm{IgG}, 1 \mathrm{mg} / \mathrm{ml}, 1: 600$ dilution, cat. no. 250713; Abbiotec, San Diego, CA, USA). The primary antibody was then detected using avidin-biotin peroxidase detection solution (Dakocytomation labelled streptavidin biotin reagent; Dakocytomation, Glostrop, Denmark and System-horseradishperoxidase; Dako, Glostrup, Denmark) and the signal was visualized using diaminobenzidine (Dakocytomation) and Substrate Chromogen-System (Dako). Slides were counterstained with Harris's hematoxylin, dehydrated, cleared and mounted. Positive controls from the appendix and tonsils were used. The cells were initially observed at a low magnification (x100) to assess the general distribution of the primary antibody. The samples were subsequently examined at a higher magnification (x400). The evaluation of cell staining was performed in tumor tissue. The tumor cells (exhibiting gross and evident nucleoli, and irregular chromatin) were identified and counted at the higher magnification. Immunohistochemical staining was evaluated in the cytoplasm of tumor cells. The intensity of staining of each section was evaluated subjectively by three separate observers (who were blinded to the experiment) using the following designations: $0-10 \%$ of cells stained, score $0 ; 11-25 \%$ of cells stained, score $1 ; 26-50 \%$ of cells stained, score $2 ; 51-100 \%$ of cells stained, score 3 . Those scoring $0-1$ were considered to be negative, and those scoring 2-3 were considered to be positive.

Statistical analysis. Data were analyzed using GraphPad Instat 3.0 software. For immunohistochemical staining, the concordance between staining intensity scores for each sample was calculated according to Cohen's $\kappa$ coefficient: $\kappa<0.4$, slight concordance; $\kappa \geq 0.4$ and $<0.8$, moderate concordance; $\kappa \geq 0.8$ and $<1$, strong concordance; and $\kappa=1$, perfect concordance. The first $\kappa$ inter-rater was between 0.8 and 1.0 of $1 \%$ (between strong and perfect concordance). All discordant cases were re-evaluated and the result was determined by consensus.

The association between staining intensity and tumor classification was evaluated using Fisher's exact test. $\mathrm{P}<0.05$ was considered to indicate a statistically significant difference.

\section{Results}

The study evaluated 28 patients, 14 with benign and 14 with malignant neoplasms. The group with benign tumors had a mean age of $37.28 \pm 13.69$ years, and mean parity of $2.14 \pm 1.70$ infants. Table I shows the qualitative variables of the patients that were evaluated, as well as the tumor staging. Table II demonstrates the histopathological features of the tumors.

The immunohistochemical analysis of benign and malignant histological sections for TNF- $\alpha$ showed absent or weak $(0-1)$ staining in nine $(64.3 \%)$ benign tumors and in six $(42.9 \%)$ malignant tumors, and moderate or strong (2-3) staining in five $(35.7 \%)$ benign tumors and in eight $(57.1 \%)$ malignant tumors. Regarding IL-10, there was absent or weak (0-1) staining in eight $(57.1 \%)$ benign tumors and $1(7.1 \%)$ malignant tumor, and moderate or strong (2-3) staining in six (42.9\%) benign tumors and $13(92.9 \%)$ malignant tumors. Immunohistochemical staining of IL-10 was more intense in malignant tumors compared with benign tumors $(\mathrm{P}=0.0128)$. Immunohistochemical staining for TNF- $\alpha$ was more intense in malignant neoplasms compared with benign neoplasms, but this difference was not statistically significant $(\mathrm{P}=0.4495)$ (Table III).

\section{Discussion}

The cytokine TNF- $\alpha$ is increased in malignant ovarian tumors compared with the normal ovarian surface epithelium (20). Several studies have demonstrated an association between inflammation and ovarian tumorigenesis, suggesting that TNF- $\alpha$ is critical in the regulation of invasion, angiogenesis, and tumor metastasis $(20,21)$. The biological activity of TNF- $\alpha$ may be modulated by its membrane surface receptors (TNF-R), which are able to bind TNF with high affinity $(22,23)$. The regulation of TNF-Rs is critical to governing the responsiveness of tumor cells to TNF- $\alpha$. High plasma levels of TNF- $\alpha$ and TNF-Rs correlated with tumor stage and a reduced mean survival time (14). The TNF-R also has a soluble form 
(sTNF-R) which acts as a specific cytokine antagonist. sTNF-R binds circulating TNF- $\alpha$ and inhibits its biological activity by preventing its binding to cellular receptors. High concentrations of sTNF-R can inhibit TNF and therefore represent a mechanism by which tumors may escape the destructive effects of TNF- $\alpha$. Although the definite pathogenic role of sTNF-Rs remains controversial, they have been proposed as reliable markers for local production of TNF- $\alpha(24,25)$.

Several studies have observed elevated TNF- $\alpha$ concentrations in the blood of ovarian cancer patients and patients with a wide variety of tumor types $(26,27)$. These studies have also demonstrated that TNF- $\alpha$ is crucial in promoting tumor growth and in the progression of ovarian malignancies $(14,16,28)$. Nowak et al (29) observed the increased production of TNF- $\alpha$ in peripheral blood mononuclear cells in patients with malignant ovarian cancer, compared with nonmalignant cases. Furthermore, the production of high levels of IL-10 and transforming growth factor- $\beta 1$ (TGF- $\beta 1$ ) by malignant cells reduces ovarian production of interferon- $\gamma($ IFN- $\gamma)$ and TNF- $\alpha$, suppressing the immune response against the tumor cells. However, TNF- $\alpha$ is not always detectable in cancer patients, and concentrations may vary between individuals and throughout the course of the disease $(25,30)$. Our results revealed no significant difference in tissue expression of TNF- $\alpha$ between malignant and benign neoplasms, which may be due to its downregulation by the activity of other cytokines, including IL-10. Further evaluation with a greater number of cases is required to provide additional insight.

IL-10 is a multifunctional cytokine, produced by Th2 lymphocytes, and may inhibit cellular immune responses. It is an inhibitor of activated macrophages, which are important in the homeostatic control of innate immune responses and cellular immunity. IL-10 may exert various effects on the immune system and is associated with angiogenesis, growth and proliferation of cancer cells, together with IL-8 (31). Studies have demonstrated that IL-10 may be involved in the progression of ovarian cancer $(15,32,33)$. The elevation of serum norepinephrine and IL-10 levels induced by chronic stress was observed to promote the growth of ovarian carcinoma in mouse models (34). TGF- $\beta 1$, vascular endothelial growth factor and IL-10 were expressed in 100, 74.69 and $54.96 \%$ of malignant tissues of epithelial ovarian cancer, respectively, suggesting that these cytokines have immunosuppressive roles (35).

Zhou et al (15) evaluated the expression of IL-10 in primary carcinomas of the ovary, and demonstrated that the tissue level of this cytokine was significantly higher in malignant tumors compared with benign tumors and normal controls. In addition, the malignant tumors had significantly higher serum and ascitic fluid IL-10 levels, suggesting that the malignant cells were able to synthesize this IL, and that it may contribute to the promotion and development of ovarian carcinoma. These findings are in agreement with the current study, which showed more intense labeling of the cytokine IL-10 in malignant compared with benign ovarian neoplasms.

In conclusion, cytokines may be useful tissue markers in determining ovarian malignancy. However, a great amount of further research into the immune profile of ovarian neoplasms is necessary before this approach may be refined for clinical use.

\section{Acknowledgements}

The authors would like to acknowledge the funding received from the CNPq (Conselho Nacional de Desenvolvimento Científico e Tecnológico), FUNEPU (Fundação de Ensino e Pesquisa de Uberaba) and the FAPEMIG (Fundação de Amparo à Pesquisa do Estado de Minas Gerais).

\section{References}

1. Siegel R, Naishadham D and Jemal A: Cancer statistics, 2013. CA Cancer J Clin 63: 11-30, 2013.

2. Dørum A, Kristensen GB, Abeler VM, Tropé CG and Møller P: Early detection of familial ovarian cancer. Eur J Cancer 32A: 1645-1651, 1996

3. Yawn BP, Wollan P, Klee M and Barrette B: Ovarian carcinoma: care and survival in a community-based population. Clin Ther 23: 146-159, 2001.

4. Padilla LA, Radosevich DM and Milad MP: Limitations of the pelvic examination for evaluation of the female pelvic organs. Int J Gynaecol Obstet 88: 84-88, 2005.

5. Minaretzis D, Tsionou C, Tziortziotis D, Michalas S and Aravantinos D: Ovarian tumors: prediction of the probability of malignancy by using patient's age and tumor morphologic features with a logistic model. Gynecol Obstet Invest 38: 140-144, 1994.

6. Osmers RG, Osmers M, von Maydell B, Wagner B and Kuhn W: Evaluation of ovarian tumors in post-menopausal women by transvaginal sonography. Eur J Obstet Gynecol Reprod Biol 77: 81-88, 1998.

7. Guerriero S, Ajossa S, Garau N, et al: Ultrasonography and color Doppler-based triage for adnexal masses to provide the most appropriate surgical approach. Am J Obstet Gynecol 192: 401-406, 2005.

8. Szpurek D, Moszyniki R,Zietkowiak W, et al: An ultrasonographic morphological index for prediction of ovarian tumor malignancy. Eur Gynaecol Oncol 26: 51-54, 2005.

9. U.S.Preventive Services Task Force: Screening for ovarian cancer: recommendation statement. Ann Fam Med 2: 260-262, 2004.

10. Fishman DA, Cohen L, Blank SV, et al: The role of ultrasound evaluation in the detection of early-stage epithelial ovarian cancer. Am J Obstet Gynecol 192: 1214-1222, 2005.

11. Negus RP, Stamp GW, Hadley J and Balkwill FR: Quantitative assessment of the leukocyte infiltrate in ovarian cancer and its relationship to the expression of C-C chemokines. Am J Pathol 150: 1723-1734, 1997.

12. Mantovani G, Macciò A, Pisano M, et al: Tumor-associated lympho-monocytes from neoplastic effusions are immunologically defective in comparison with patient autologous PBMCs but are capable of releasing high amounts of various cytokines. Int J Cancer 71: 724-731, 1997.

13. Dobrzycka B, Terlikowski SJ, Kowalczuk O and Kinalski M: Circulating levels of TNF-alpha and its soluble receptors in the plasma of patients with epithelial ovarian cancer. Eur Cytokine Netw 20: 131-134, 2009.

14. Charles KA, Kulbe H, Soper R, et al: The tumor-promoting actions of TNF-alpha involve TNFR1 and IL-17 in ovarian cancer in mice and humans. J Clin Invest 119: 3011-3023, 2009.

15. Zhou J, Ye F, Chen H, Lv W and Gan N: The expression of interleukin-10 in patients with primary ovarian epithelial carcinoma and in ovarian carcinoma cell lines. J Int Med Res 35: 290-300, 2007.

16. Tavares-Murta BM, Cunha Fde Q, Miranda R, Adad SJ and Murta EFC: Differential tumor microenvironment in human ovarian cystic tumors. Tumori 90: 491-497, 2004.

17. Murta EF, da Silva CS, Gomes RA, et al: Ultrasonographic criteria and tumor marker assay are good procedures for the diagnosis of ovarian neoplasia in preselected outpatients. Eur J Gynaecol Oncol 25: 707-712, 2004.

18. Murta EF and Nomelini RS: Early diagnosis and predictors of malignancy of adnexal masses. Curr Opin Obstet Gynecol 18: 14-19, 2006.

19. No authors listed: International Federation of Gynecology and Obstetrics annual report on the results of treatment in gynecologic cancer. Int J Gynaecol Obstet 28: 189-190, 1993.

20. Szlosarek PW, Grimshaw MJ, Kulbe H, et al: Expression and regulation of tumor necrosis factor alpha in normal and malignant ovarian epithelium. Mol Cancer Ther 5: 382-390, 2006. 
21. Sethi G, Sung B and Aggarwal BB: TNF: a master switch for inflammation to cancer. Front Biosci 13: 5094-5107, 2008.

22. Balkwill F: Tumor necrosis factor or tumor promoting factor? Cytokine Growth Factor Rev 13: 135-14, 2002.

23. Bertazza L and Mocellin S: Tumor necrosis factor (TNF) biology and cell death. Front Biosci 13: 2736-2743, 2008

24. Anderson GM, Nakada MT and DeWitte M: Tumor necrosis factor-alpha in the pathogenesis and treatment of cancer. Curr Opin Pharmacol 4: 314-320, 2004.

25. Szlosarek PW, Grimshaw MJ, Wilbanks GD, et al: Aberrant regulation of argininosuccinate synthetase by TNF-alpha in human epithelial ovarian cancer. Int J Cancer 121: 6-11, 2007.

26. Gadducci A, Ferdeghini M, Castellani C, et al: Serum levels of tumor necrosis factor (TNF), soluble receptors for TNF (55and 75-kDa sTNFr), and soluble CD14 (sCD14) in epithelial ovarian cancer. Gynecol Oncol 58:184-188, 1995.

27. Radke J, Schmidt D, Böhme M, et al: Cytokine level in malignant ascites and peripheral blood of patients with advanced ovarian carcinoma. Geburtshilfe Frauenheilkd 56: 83-87, 1996 (in German).

28. Hassan F, Islam S, Tumurkhuu G, et al: Involvement of interleukin-1 receptor-associated kinase (IRAK)-M in toll-like receptor (TLR) 7-mediated tolerance in RAW 264.7 macrophage-like cells. Cell Immunol 256: 99-103, 2009.

29. Nowak M, Klink M, Glowacka E, et al: Production of cytokines during interaction of peripheral blood mononuclear cells with autologous ovarian cancer cells or benign ovarian tumour cells. Scand J Immunol 71: 91-98, 2010.
30. Daraï E, Detchev R, Hugol D and Quang NT: Serum and cyst fluid levels of interleukin (IL) -6,IL-8 and tumour necrosis factor-alpha in women with endometriomas and benign and malignant cystic ovarian tumours. Hum Reprod 18: 1681-685, 2003.

31. Kozłowski L, Zakrzewska I, Tokajuk P and Wojtukiewicz MZ: Concentration of interleukin-6 (IL-6), interleukin-8 (IL-8) and interleukin-10 (IL-10) in blood serum of breast cancer patients. Rocz Akad Med Bialymst 48: 82-84, 2003.

32. Rabinovich A, Medina L, Piura B and Huleihel M: Expression of IL-10 in human normal and cancerous ovarian tissues and cells. Eur Cytokine Netw 21: 122-128, 2010.

33. Yigit R, Massuger LF, Figdor CG and Torensma R: Ovarian cancer creates a suppressive microenvironment to escape immune elimination. Gynecol Oncol 117: 366-72, 2010.

34. Gao G, Sun J, Gao J, Xiong L, Yu L and Gao Y: Chronic stress promoted the growth of ovarian carcinoma via increasing serum levels of norepinephrine and interleukin-10 and altering $\mathrm{nm} 23$ and NDRG1 expression in tumor tissues in nude mice. Biosci Trends 7: 56-63, 2013.

35. Liu CZ, Zhang L, Chang XH, et al: Overexpression and immunosuppressive functions of transforming growth factor 1, vascular endothelial growth factor and interleukin-10 in epithelial ovarian cancer. Chin J Cancer Res 24: 130-137, 2012. 